\title{
Pengaruh Pengendalian Integrated Port Time (IPT) terhadap Kelancaran Kegiatan Bongkar Muat di PT. Pertamina (Persero) Regional IV Semarang
}

\author{
Barokhah Ardian ${ }^{1}$, Retno Indriyati ${ }^{2}$ \\ ${ }^{1,2}$ Politeknik Bumi Politeknik, Semarang \\ $\underline{1 \text { barokahardian24@gmail.com, }}, \underline{2}$ retno@akpelni.ac.id
}

Diterima 12 Desember 2020, direvisi 08 Januari 2021, diterbitkan 08 Maret 2021

\begin{abstract}
Abstrak
Penelitian ini bertujuan untuk mengkaji pengaruh pengendalian sistem Integrated Port Time (IPT) terhadap kelancaran kegiatan bongkar muat di PT. Pertamina (Persero) Regional IV Semarang. Penulis melakukan pengamatan di PT. Pertamina (Persero) Regional IV Semarang, selain itu juga melakukanWawancara dengan orang-orang yang terkait dengan permasalahan yang dibahas tepatnya pada fungsi Marine dimana terdapat beberapa hal yang menjadi masalah dalam menjalankan sistem Integrated Port Time tersebut yaitu tingginya waktu tunggu di Pelabuhan yang berimplikasi terhadap biaya angkut, Lamanya waktu kapal di terminal dipengaruhi banyak faktor yang melibatkan fungsi Refinery Unit, S\&D, Domas dan Aviasi serta Shipping. Selain itu, kendala infrastruktur darat dan kapal yang masih belum memadai mengakibatkan operasional menjadi terhambat. Penulis juga mengumpulkan literatur dari buku-buku, aturanaturan dan penelitian yang terkait dengan Intregated Port Time dan Bongkar Muat. Hasil pembahasan menunjukkan bahwa ada Pengaruh Intregated Port Time terhadap kelancaran bongkar muat di PT. Pertamina (Persero) Regional IV Semarang. Hal ini dapat dibuktikan dengan Tingginya waktu tunggu di Pelabuhan yang merupakan salah satu penghambat Integrated Port Time (IPT), hal ini dikarenakan adanya Waiting Time, Terminal Time, Lab Time Score, Marine Time dan Finance Ops Time. Lamanya waktu kapal pada saat di terminal mengakibatkan operasi penyaluran BBM menjadi terlambat dan infrastruktur darat dan Kapal yang masih belum memadai.
\end{abstract}

Kata kunci: Pengendalian, Integrated Port Time (IPT), Bongkar Muat

\begin{abstract}
This study aims to know the control pengaruruh Integrated Port Time (IPT) system on the smooth running of loading and unloading activities at PT. Pertamina (Persero) Regional IV Semarang. The author made observations at PT. Pertamina (Persero) Regional IV Semarang, besides that, also conducted interviews with people related to the problems discussed precisely in the Marine Function where there were several things that became problems in running the Integrated Port Time system, namely the high waiting time at the Port which had implications for costs. transportation, the length of time the ship at the terminal is influenced by many factors involving the functions of the Refinery Unit, $S \& D$, Domas and Aviation and Shipping. In addition, the inadequate constraints on land and ship infrastructure have resulted in hampered operations. The author also collects literature from books, regulations and research related to integrated port time and loading and unloading. The results of the discussion show that there is an effect of integrated port time on the smooth loading and unloading process at PT. Pertamina (Persero) Regional IV Semarang. This can be proven by the high waiting time at the port which is one of the obstacles to the Integrated Port Time (IPT), this is due to the Waiting Time, Terminal Time, Lab Time Score, Marine Time and Finance Ops Time, the length of time the ship is at the terminal. resulting in delayed fuel distribution operations and inadequate ship and land infrastructure.
\end{abstract}

Keywords: Control, Integrated Port Time (IPT), Loading and Unloading 


\section{Pendahuluan}

Pertamina adalah sebuah perusahaan milik negara yang bergerak di bidang energi yang meliputi minyak dan gas serta energi baru dan terbarukan. Dalam menjalankan bisnisnya Pertamina berdasar pada prinsip-prinsip tata kelola korporasi yang baik agar supaya dapat bersaing dan mempunyai daya saing yang tinggi. Dengan memiliki pengalaman yang lebih dari 61 tahun, Pertamina semakin berkomitmen dan percaya diri dalam menjalankan kegiatan bisnisnya secara profesional, mempunyai wawasan dan penguasaan teknis yang tinggi mulai dari kegiatan dari hulu sampai hilir. Pertamina berkomitmen untuk selalu berorientasi pada pelanggan agar dapat berperan dalam memberikan nilai tambah bagi kemajuan dan kesejahteraan bangsa Indonesia.

Salah satu komitmen Pertamina adalah selalu berupaya pada perbaikan dan inovasi sesuai tuntutan kondisi global dalam setiap kegiatannya menjalankan peran strategis dalam perekonomian nasional Indonesia. Saat ini Pertamina mencangkan program Semangat terbarukan yang menjadi salah satu bukti bahwa Pertamina berkomitmen dalam menciptakan alternatif baru dalam penyediaan sumber energi yang efisien, berkelanjutan dan berwawasan lingkungan. Berinisatif dalam memanfaatkan sumber daya yang ada dan potensi sumber daya yang dimiliki untuk mendapatkan sumber energi baru dan terbarukan, dengan mantap Pertamina bergerak maju untuk mewujudkan visi perusahaan yaitu Menjadi Perusahaan Energi Nasional Kelas Dunia.

Dalam melayani kebutuhan energi dalam negeri, Pertamina mempunyai 8 Unit Pengolahan yang terdiri dari Refinery Unit Dumai, Refinery Unit Plaju, Refinery Unit Cilacap, Refinery Unit Balikpapan, Refinery Unit Balongan, Refinery Unit Kasim. Dalam penyaluran BBM ke seluruh Indonesia Pertamina mempunyai armada kapal yang beroperasi sejumlah 295 kapal yang terdiri dari 65 kapal milik dan 230 kapal charter. Kapalkapal tersebut menyalurkan BBM ke berbagai Terminal BBM di Indonesia termasuk Terminal BBM Semarang yaitu Marine Region IV.

Pertamina (Persero) Marine Region IV ini merupakan salah satu bagian dari Perusahaan Pertamina. Perusahaan tersebut mempunyai tugas menjalankan bagian shipping di PT. Pertamina (Persero) Region IV salah satunya membantu proses discharging pada kapal-kapal yang menyuplai BBM dan Gas. Pertamina telah melakukan Transformasi Pelabuhan (Port Transformation) dalam penyaluran minyak melalui laut. Program transformasi pelabuhan yang sedang dilaksanakan tidak hanya fokus pada Lay Time, tetapi sudah memiliki formulasi Integrated Port Time (IPT) yang lebih komprehensif. Dengan menggunakan konsep ini, setiap kapal di pelabuhan dari Actual Time Arrival (ATA) sampai Actual Time Departure (ATD) dihitung dan dipertanggung jawabkan.

Penelitian ini bertujuan untuk mengkaji pengaruh/dampak pengendalian sistem Integrated Port Time (IPT) terhadap kelancaran kegiatan bongkar muat di PT. Pertamina (Persero) Regional IV Semarang. Penulis tertarik untuk meneliti karena adanya beberapa permasalahan yang mengakibatkan proses penyaluran $\mathrm{BBM}$ menjadi terlambat dan mengakibatkan kerugian. Hal ini disebabkan karena : Tingginya waktu tunggu di pelabuhan yang berimplikasi terhadap biaya angkut, lamanya waktu kapal di terminal dipengaruhi banyak faktor yang melibatkan fungsi Refinery Unit, S\&D, Domgas dan Aviasi, disamping Shipping, dan kendala infrastruktur darat dan kapal yang masih belum memadai.

\section{Materi dan Metode}

\section{Pengertian Pengendalian}

Pengendalian secara umum adalah sebagai proses penentuan, apa yang harus dicapai yaitu standar, apa yang sedang di lakukan yaitu pelaksanaan, menilai pelaksanaan dan apabila perlu melakukan perbaikan perbaikan, sehingga pelaksanaan sesuai dengan rencana yaitu selaras dengan standar. Sistem pengendalian manajemen sebagai usaha terdiri dari melihat bahwa segala sesuatu yang sedang dilakuan sesuai dengan rencana yang telah diadopsi, perintah yang telah diberikan, dan prinsip-prinsip yang telah ditetapkan. Jadi berdasarkan uraian diatas dapat di tarik kesimpulan bahwa pengendalian merupakan pemantauan, pemeriksaan dan evaluasi yang dilakukan oleh atasan atau pimpinan dalam organisasi terhadap komponen organisasi dan sumber-sumber yang ada untuk mencapai tujuan yang telah ditetapkan sebelumya, secara terus menerus dan berkesinambungan agar semua dapat berfungsi 
secara maksimal sehingga tujuan organisasi dapat tercapai secara efektif dan efisien.

\section{Integrated Port Time (IPT)}

Pedoman Integrated Port Time, disahkan oleh Direktur Utama dan diberlakukan per tanggal 20 Mei $2010 \quad$ (No.A-009/F20000/2010-S0) Pedoman Integrated Port Time, disahkan oleh Direktur Utama dan diberlakukan per tanggal 20 Mei $2010 \quad$ (No. A-009/F20000/2010-S0) Integrated Port Time (IPT) di PT. Pertamina (Persero) adalah batasan waktu yang dilakukan oleh kapal sejak kapal datang, bongkar/muat sampai dengan berangkat kembali.

Pedoman Integrated Port Time telah disahkan oleh Direktur Utama dan diberlakukan per tanggal 20 Mei 2010 (No. A-009/F20000/2010S0) [1]. Proses pembuatan Integrated Port Time tersebut yaitu :

1. Identifikasi dan pengumpulan data atas aktivitas-aktivitas di pelabuhan, khususnya pada :

a. Fungsi yang bertanggung jawab

b. Standard Time masing-masing aktivitas

2. Identifikasi dan pengumpulan data atas isuisu / skenario-skenario yang mungkin terjadi, dengan menggunakan tools VIFA.

3. Integrasi dengan MMHM (Management Material Hydro Movement).

Perhitungan IPT didasarkan atas Sub Proses yang dilakukan mulai dari kedatangan kapal sampai dengan keberangkatan kapal. Sub Proses tersebut antara lain yaitu :

1. Waiting Time (Waktu menunggu di pelabuhan baik itu di inner pool maupun di jetty)

2. Terminal Time (Waktu kegiatan kapal di terminal berdasarkan standarisasi waktu)

3. Lab Time Score (Waktu kegiatan lab test kapal di pelabuhan)

4. Marine time (Waktu marine kapal di pelabuhan seperti steaming in/out, berthing, dan port clearence)

5. Finance Ops. Time (Waktu kegiatan penguRefinery Unitsan dokumen).

Adapun Penentuan Waktu Standar di setiap proses sebagai berikut :

1. Tujuan

a. Mengetahui Proses mana saja yang melebihi waktu standar dan melakukan analisis akar masalah b. Waktu standart yang telah ditentukan menjadi acuan setiap kapal yang beroprasi dipelabuhan

\section{Tata Cara}

a. Menganalisis Historical Data

b. Site Visit dan melakukan pengukuran secara langsung

c. Challenge Session

3. Prinsip

Target waktu yang ditentukan dan dapat dicapai

4. Asumsi

Kondisi Normal tanpa waktu penungguan didalamnya (perfect condition)

Dalam perhitungan IPT terdapat 3 macam sebagai berikut :

1. IPT Baseline

Yaitu IPT yang dihitung berdasarkan data historis pelabuhan tersebut berdasar hasil challenge session.

2. IPT Target

Yaitu IPT yang dihitung berdasar kesepakatan oleh unit setempat melalui perbaikan perencanaan infrasruktur, sehingga nilai target IPT berada diantara baseline dan standar IPT.

3. IPT Standar

Yaitu IPT yang dihitung berdasarkan asumsi tidak ada waktu penungguan di dalamnya.

\section{Pengertian Pelabuhan}

Menurut Undang-Undang No. 17 Tahun 2008 mengenai Pelayaran, pelabuhan adalah tempat yang terdiri atas daratan dan atau perairan dengan batas-batas tertentu sebagai tempat berkegiatan pemerintah dan perusahaan. Secara fisik, pelabuhan dipergunakan sebagai tempat kapal berlabuh, naik turunnya penumpang dan atau bongkar muat barang [2]. Sedangkan fungsi pelabuhan menurut Lasse adalah sebagai Gateway yang artinya pelabuhan berfungsi sebagai pintu yang dilalui oleh orang dan barang kedalam maupun keluar pelabuhan yang bersangkutan. Sebagai Link artinya bahwa keberadaan pelabuhan pada hakekatnya memfasilitasi pemindahan barang muatan antara moda transportasi darat (inland transport) dan moda transportasi laut (maritime transport). Pelabuhan sebagai Interface adalah pelabuhan sebagai tempat pemindahan barang dan menjembatani kapal dengan truk/kereta api atau truk/kereta api dengan kapal. Sedangkan pelabuhan sebagai 
industrial Entity adalah bahwa apabila pelabuhan dikelola dengan baik maka akan menyuburkan bidang usaha lain sehingga area pelabuhan menjadi zona indutri terkait dengan kepalabuhanan [3].

\section{PT. Pertamina (Persero)}

Pertamina (Persero) adalah perusahaan Pertambangan Minyak dan Gas Bumi Negara) atau nama resminya PT.Pertamina (Persero) adalah sebuah BUMN yang bertugas mengelola pertambangan minyak dan gas bumi di Indonesia. Wilayah operasional dan kerja sama PT. Pertamina (Persero) dengan Anak Perusahaan serta perusahaan Patungan khususnya di wilayah Indonesia dan Wilayah Kerja Manca Negara.

PT.Pertamina (Persero) mempunyai Jaringan Anak Perusahaan sebagai berikut [4]: (1) PT. Pertamina EP; (2) PT. Pertamina Geothermal Energy; (3) PT. Pertamina Hulu Energi; (4) PT. Pertamina EP Cepu; (5) PT. Pertamina Drilling Services Indonesia; (6) PT. Tugu Pratama IndonesiaPertamina; (7) Pertamina Drilling Services Indonesia; (8) PT. Pertamina Dana Ventura; (9) PT. Pertamina Bina Medika; (10) PT. Patra Jasa; (11) PT. Pelita Air; (12) PT. Pertamina Gas; (13) PT. Pertamina Patra Niaga; (14) PT Pertamina Patra Niaga; (15) PT. Pertamina Trans Kontinental; (16) PT. Pertamina Retail; (17) PT. Pertamina Training \& Consulting; (18) PT. Nusantara Regas; (19) PT. Dana Pensiun Pertamina; (20) PT. Patra Dok Dumai

\section{Metode}

Metode pengumpulan data yang dapat dilakukan antara lain dengan studi pustaka, wawancara dan observasi. Alat untuk memperoleh keterangan dari obyek atau elemen antara lain : daftar pertanyaan (questionaire), wawancara dan observasi atau pengamatan langsung [5]. Data angket disajikan dalam bentuk tabel, dan dalam kalimat deskriptif didasarkan dari data perhitungan statistik, disajikan dengan kalimat yang bersifat deskriptif dan berupa narasi yang mudah dipahami. Sedangkan metode wawancara menurut Moh. Yamin ada tiga, yaitu wawancara bebas, wawancara terpimpin, dan wawancara bebas terpimpin. Jenis wawancara yang dipilih dalam penelitian ini adalah wawancara bebas, yang dilakukan dengan responden non random sampling. Data sekunder adalah data yang diperoleh melalui bahan kepustakaan [6]. Sedangkan menurut Sugiyono pengumpulan data dapat dilakukan dalam berbagai setting, berbagai sumber dan berbagai cara [7]. Pengumpulan data ini dilakukan dengan studi kepustakaan (library research).

\section{Hasil dan Pembahasan}

Bagian ini berisikan mengenai hasil-hasil yang didapatkan dengan menggunakan metode yang telah diterangkan dalam bagian sebelumnya

1. Tingginya Waktu Tunggu di Pelabuhan yang Berimplikasi Terhadap Biaya Angkut

Tingginya waktu tunggu di Pelabuhan merupakan salah satu penghambat Integrated Port Time (IPT). Beberapa permasalahan yang mengakibatkan tingginya waktu tunggu kapal di Pelabuhan antara lain adalah :

\section{a. Waiting Time}

Yaitu waktu ketika kapal menunggu di pelabuhan baik itu di inner pool maupun di jetty dihitung saat kapal tiba sampai dengan ketika Pandu naik di atas kapal.

\section{b. Terminal Time}

Yaitu waktu kegiatan kapal di terminal berdasarkan standarisasi waktu dihitung saat kapal selesai kegiatan sandar (All Fast) sampai dengan Hose Disconnect. Meliputi: Pumping rate negotiation time, Hose connect time, Electricity request for pump time, Hose disconnect time, and Cargo calculation time.

\section{c. Lab Time Score}

Yaitu waktu selama kegiatan tes laboraturium kapal saat sandar di jetty atau melakukan bongkar/muat dihitung saat pengambilam sample sampai dengan hasil laboraturium keluar. Meliputi: Lab analysis I, Lab analysis II, and Lab analysis III.

\section{d. Marine Time}

Yaitu waktu marine kapal di pelabuhan (Steaming in/out, berthing, and port clearence) dihitung saat kapal tiba sampai dengan selesai sandar (All Fast) dan dihitung saat Hose Disconnect sampai dengan kapal Full Away.

e. Finance Ops Time

Yaitu waktu kegiatan pengurangan dokumen dihitung saat keluarnya SFAL (Ship Figure After Loading) sampai 
dengan selesainya dan diterimanya BL (Bill Of Lading).

2. Upaya Mengurangi Waktu Tunggu di Pelabuhan

\section{a. Reduce Waiting Jetty}

Yaitu mengurangi waktu tunggu untuk sandar di jetty dengan cara perubahan pola supply dan penambahan/perbaikan pada sarana prasarana. Pola supply disini yaitu berhubungan dengan tata cara manajemen pihak jetty/darat dalam supply BBM ke kapal. Dalam kegiatan bongkar/muat di jetty jika pola supply mengalami kendala maka berakibat pada lamanya kapal di jetty yang mempengaruhi kapal-kapal lain akan menunggu untuk menggantikan sandar. Disamping itu sarana prasarana juga menjadi acuan dalam efektivitas operasional di jetty. Dalam hal ini jika sarana prasarana mengalami kerusakan maka akan mengulur waktu saat kegiatan bongkar/muat di jetty yang berakibat pada kapal-kapal yang menunggu untuk sandar.

\section{b. Reduce Waiting Ullage}

Yaitu mengurangi waktu tunggu dikarenakan menunggu ullage pada tangki timbun darat dengan cara pengiriman jumlah dan jenis kargo yang sesuai dengan forecast stock sales sehingga operasional kapal berjalan lancar dan tidak ada waktu yang tertunda. Dalam pengiriman jumlah dan jenis kargo telah diatur oleh programmer kapal dan telah disesuaikan dengan kebutuhan BBM.

c. Reduce Waiting Tide

Yaitu mengurangi waktu tunggu dikarenakan pasang surut dengan cara pengerukan secara berkala atau menerapkan sistem STS (Ship To Ship). STS (Ship To Ship) adalah proses transfer/pemindahan cargo antar kapal yang diposisikan berdampingan satu sama lain, baik saat diam atau sedang berlangsung.

3. Faktor Penyebab Lamanya Waktu Kapal di Terminal

Lamanya waktu kapal di terminal dapat mengakibatkan operasi penyaluran BBM menjadi terlambat. Keterlambatan ini berdampak buruk bagi Perusahaan dan Masyarakat. Beberapa factor yang mempengaruhi melibatkan fungsi refinery unit, s\&d, domgas dan aviasi, disamping shipping Faktor lain yaitu:

a. Proses bongkar/muat dengan sistem grade by grade

Proses bongkar/muat dengan sistem grade by grade yaitu kapal dalam muat atau bongkar menerapkan sistem berurutan antara muatan satu dengan yang lainnya. Dengan sistem ini akan memakan banyak waktu di Pelabuhan dan kurang efisien.

b. Performa pompa-pompa kargo diatas kapal yang belum memenuhi standar

c. Pompa-pompa kargo diatas kapal adalah salah satu hal yang menjadi hal yang dipertimbangkan pada saat bongkar muatan. Jika performa pompa-pompa kargo belum memenuhi standar maka akan mengakibatkan proses bongkar muatan menjadi terhambat atau melebihi waktu standar.

4. Upaya Penanganan Lamanya Waktu Kapal di Terminal

a. Menerapkan Sistem Simultan Kargo

Sistem Simultan Kargo pada saat kapal bongkar/muat yaitu melakukan proses bongkar/muat dengan 2 kargo sekaligus dalam waktu yang bersamaan. Dengan sistem ini akan lebih meminimalisir waktu 6-8 jam dibandingkan dengan sistem grade by grade.

b. Melakukan Standarisasi Pompa Kargo di atas Kapal

Standarisasi pompa-pompa kargo dilakukan dengan cara maintenance secara berkala guna memenuhi standar rate pada saat bongkar muatan dan dapat meminimalisir waktu.

5. Kendala Infrastur Darat dan Kapal

Infrastruktur darat dan kapal sangat mempengaruhi kelancaran operasional kapalkapal dan berakibat pada IPT. Kendalakendala yang ada di PT. Pertamina (Persero) Regional IV Semarang antara lain adalah :

a. PT. Pertamina (Persero) Regional IV Semarang hanya mempunyai 1 (Satu) sarana tambat kapal yaitu Single Buoy Mooring (SBM) kapasitas DWT 30.000 MT, panjang kapal LOA 131-185 meter dan draft kapal maksimal 9 meter. Dalam hal ini mestinya perusahaan memiliki sarana tambat lebih dari satu guna mengantisipasi apabila terjadi kerusakan pada SBM. 
b. Infrastruktur di atas kapal sangat berguna untuk mendukung kelancaran operasional yaitu Crane, Cargo Pump, Manifold, Emergency Shut Down (EMS), dan sebagainya. Infrastruktur tersebut kebanyakan di atas kapal mengalami kendala/kerusakan. Yang sering ditemui yaitu performa Crane dan Pompa-pompa Kargo yang belum sesuai standar sehingga mengakibatkan operasional terganggu/ terhambat.

6. Upaya Meningkatkan Infrastruktur Darat dan Kapal

a. Meningkatkan Infrastruktur Darat/ Pelabuhan

Infrastruktur darat yang belum memadai berdampak pada efisien waktu. Seperti di Pelabuhan Khusus Pertamina Semarang yang hanya memiliki satu SBM (Single Buoy Mooring) untuk penyandaran kapal dengan kapasitas DWT 30.000 MT, panjang kapal LOA 131-185 meter dan draft kapal maksimal 9 meter. Untuk meningkatkan infrastruktur bisa dengan terobosan sebagai berikut : (1) Menambah infrastruktur SBM (Single Buoy Mooring) dengan kapasitas yang berbeda guna meningkatkan penyaluran BBM untuk wilayah Semarang dan DIY; (2) Menambah Tangki Timbun Darat guna meningkatkan kapasitas BBM seiring bertambahnya SBM (Single Buoy Mooring).

b. Meningkatkan Infrastruktur Kapal

Selama proses bongkar/muat masih ditemukan kapal-kapal yang infrastrukturnya kurang memadai sehingga berdampak pada efisien waktu. Yang sering terjadi yaitu proses bongkar muatan yang melebihi waktu atau slow rate dikarenakan performa pompa-pompa kargo pada kapal yang belum memenuhi standar. Selain itu ada faktor lainnya seperti crane yang mengalami kerusakan sehingga akan menghambat operasi bongkar/muat. Untuk meningkatkan infrastruktur di atas kapal harus melakukan perbaikan/peningkatan guna memenuhi standar sebagai berikut : (1) Performa pompa-pompa cargo yang memenuhi standar rate yang telah disetujui pihak kapal dan pihak darat; (2) Crane yang digunakan pada saat proses bongkar/muat harus dalam kondisi baik;
(3) Emergency Shut Down (ESD) pada kapal harus dalam kondisi baik dan tidak ada kendala; (4) Manifold kapal harus dalam kondisi yang baik atau tidak ada kebocoran.

\section{Kesimpulan}

Dari pembahasan tersebut dapat disimpulkan bahwa Integrated Port Time (IPT) di PT. Pertamina (Persero) Regional IV Semarang, berpengaruh terhadap kelancaran kegiatan bongkar muat. Hal ini dikarenakan :

1. Tingginya waktu tunggu kapal pada saat di pelabuhan yang diakibatkan dari faktor jetty, ullage, tide, dan pumping rate yang berakibat pada biaya angkut.

2. Keterlambatan/lamanya kapal di salah satu terminal yang diakibatkan karena belum diterapkannya sistem simultan kargo dan performa pompa-pompa kargo di atas kapal belum memenuhi standar sehingga kegiatan bongkar muatan mengalami keterlambatan (slow rate).

3. Kendala infrastruktur darat dan kapal yang masih kurang sehingga perlu adanya peningkatan/ penambahan infrastruktur.

\section{Ucapan terima kasih}

Dalam menyelesaikan penelitian ini penulis mendapatkan bimbingan dan motivasi dari berbagai pihak, untuk itu penulis mengucapkan terima kasih kepada manajemen PT. Pertamina (Persero) Regional IV Semarang yang telah memberikan waktu dan kesempatan kepada penulis untuk melakukan penelitian ini.

\section{Daftar Pustaka}

[1] Port Time, disahkan oleh Direktur Utama dan diberlakukan per tanggal 20 Mei 2010 (No. A-009/F20000/2010-S0)

[2] Undang-Undang No. 17 Tahun 2008 tentang Pelayaran

[3] Lasse, "Manajemen Kepelabuhan", Rajagrafindo Persada, Jakarta, 2014

[4] Ihsan Mubarak, "Analisis Desain Sistem Informasi Jasa Pelabuhan di Terminal Khusus Migas PT. PERTAMINA (Persero) Balongan", Diambil dari http://repository.unpas.ac.id/view/creators/I HSAN_MUBARAK $=3 \mathrm{~A} 133010268=3 \mathrm{~A}=3$ A.html (Diakses tanggal 20 Januari 2020, jam 09.46), 2016. 
[5] J. Supranto, "Metode Penelitian Hukum dan Statistik", PT Rineka Cipta, Jakarta, 2003, hlm 2.

[6] Moh. Yamin, "Pelatihan Peningkatan Kualitas Penelitian Hukum : Metode Penelitian Hukum Normatif dan Empirik serta Aplikasinya”, Fakultas Hukum UNS, Surakarta, 2007, hlm.4.

[7] Sugiyono, "Metode Penelitian Bisnis", CV. Alfa Beta Bandung, 2011, hlm. 129. 